\title{
A CAD Material Skeleton-Based Approach for Sustainable Design
}

\author{
Egon OSTROSI ${ }^{\mathrm{a}, 1}$, Jean-Bernard BLUNTZER ${ }^{\mathrm{a}}$ and Josip STJEPANDIĆ ${ }^{\mathrm{c}}$ \\ a Université de Bourgogne Franche-Comté, UTBM, Pôle ERgonomie et COnception des \\ Systèmes ERCOS/ELLIADD EA4661, Belfort, FRANCE \\ ${ }^{\mathrm{c}}$ PROSTEP AG, Darmstadt, Germany
}

\begin{abstract}
In recent years, the development and application of sustainable product design have become a hot spot. With the development of computer technology as the core of the comprehensive technology, product management information system should integrate the sustainable material specifications early in process design. This paper proposes a conceptual model based on the concept of CAD skeleton where the material and function of the constituent elements are highly integrated to achieve sustainable products. A skeleton contains formally the following information: engineering requirements, performance requirements, materials and morphology. This information is defined by defined firstly by attachment, which relates to the immediate proximity of the importing and exporting of design loads; secondly by the functional structure which defines the simplified morphology to channel the loads and thirdly the envelope, which defines where the morphology of the part can be without interfering with others. Using the proposed formalism, the morphology of the product (geometry and topology) is formally driven by material requirements. Therefore, this approach allows the designer to design different product forms according to the material requirements of clients. An application shows the interest of the approach.
\end{abstract}

Keywords. Sustainable Design, Design for Material, CAD, Skeleton.

\section{Introduction}

The implementation of transdisciplinary engineering methods has brought materials engineers into the design process at an earlier stage. Materials and manufacturing are closely linked to determining the final product performance. New requirements have emerged for the materials of the sustainable product. The efficiency of the use of the material should be increased following the principle the just material is in the right place and just the necessary followed by the just material is in the right place [1].

The structure and the morphology of CAD product depend on many factors such as loading, materials, production methods, the structure of the product, joining and locating of parts, or appearance [2]. There is a necessity is to consider all these factors for establishing a sustainable design. It means that design should stably resist the changes [3]. Thus, modelling should reduce the random search process, minimize the iterative trial-and-error process [4] and endow the computer-aided design with creative power through the creation of the scientific methodologies [5]. Therefore, CAD modelling

\footnotetext{
${ }^{1}$ Corresponding Author, Mail: egon.ostrosi@utbm.fr.
} 
should be based on a theoretical foundation based on logical and rational thought processes.

Based on this assumption, a new approach that allows the product geometry and structure to be driven by the material specifications for sustainable design is proposed. This Design for the Material approach is implemented in a CAD system.

The remainder of this paper is structured as follows: In Section 1 the skeleton model is briefly introduced, followed by a formal model in Section 2. Section 3 describe an application of the formal model and Section 4 summarizes the conclusions and outlook.

\section{Skeleton Model}

A CAD skeleton holds the morphology of the future product [6]. The main objective of the skeleton is to validate in early phases of the CAD process the major specifications without spending time to define a detailed CAD model which will be reworked afterwards [7]. Skeleton is a basic concept in CAD modelling of machines and mechanisms [8][9]. Many researches have already been carried out using the skeleton based modelling [10-13].

Different types of skeletons and their roles in modelling are introduced in CAD modelling: part skeleton, assembly skeleton and motion skeleton [6]. Depending on the level of conceptualization, a skeleton is a simplified shape which is driven by functional requirements (FR) and embeds the design working principles [2].

A material skeleton solution represents thus the architecture of a product by defining the relationships between its simplified components to satisfy the material performances. Thus, the material selection will drive the morphology of the product.

The simplified model is enriched gradually to satisfy the whole set of functional requirements and material requirements and constraints imposed on the product.

A skeleton should formally contain the following information:

(a) Engineering requirements - design loads, performance requirements;

(b) Materials and

(c) Morphology.

On the other hand, the morphology is defined formally by:

- interfaces, which relates to the immediate proximity of the importing and exporting of design loads;

- $\quad$ architecture, which defines the simplified morphology to channel the loads;

- an envelope which defines where the morphology of the part can be without interfering with others.

\section{A formal model for CAD Material Skeleton}

Ideal modelling requires that the functions of the design are independent of each other. In the ideal case of total independence, the mapping FR to design parameters should show an uncoupled design. It means that each design parameter can be manipulated to meet a particular FR without affecting the other parameters or functions [2].

To generate in the first hand the material skeleton and in the second hand the morphology, we propose to split the FR into two types: (a) material requirements and (b) 
morphology requirements. This will allow the management of inputs for both, skeleton and morphology.

The selection of the proper materials for a design is a key step in the design process because it links early computing with the morphology of CAD models [14]. In computeraided solid modelling, the designer defines the morphology and general dimensions of components. The product configuration thus depends on material selection. Equation 1 shows that architecture and the morphology of the product depend on material selection.

$\left[\begin{array}{c}\text { Specify Material Requirements } \\ \text { Specify Architecture Requirements } \\ \text { Specify Morphology Requirements }\end{array}\right]=\left[\begin{array}{ccc}a_{11} & & \\ a_{21} & a_{22} & \\ a_{31} & a_{32} & a_{33}\end{array}\right]\left[\begin{array}{l}\text { Material Selection } \\ \text { CAD Architecture } \\ \text { CAD Morphology }\end{array}\right]$

It is the skeleton which defines the CAD architecture following the selection of the materials. The CAD morphology then depends on the skeleton.

The CAD architecture is defined by a CAD skeleton, which holds the morphology of the future product. The CAD morphology is defined by CAD part body design which supports and channel loads. However, the functional requirement "support and channel loads" depends on the material skeleton. Equation 2 shows this dependency.

$\left[\begin{array}{c}\text { Hold the Body of the Product } \\ \text { Support and Channel Loads }\end{array}\right]=\left[\begin{array}{ll}b_{11} & \\ b_{21} & b_{22}\end{array}\right]\left[\begin{array}{c}\text { Material Skeleton } \\ \text { CAD Part Body }\end{array}\right]$

Knowing that a material skeleton should import and export loads, channel the loads and no allow the interfering with other CAD parts, the managed dependency between these functional requirements is shown by equation 3 .

$\left[\begin{array}{c}\text { Import/Export Loads } \\ \text { Channel Loads } \\ \text { No Interfering }\end{array}\right]=\left[\begin{array}{lll}c_{11} & & \\ c_{21} & c_{22} & \\ c_{31} & c_{32} & c_{33}\end{array}\right]\left[\begin{array}{c}\text { CAD Interface } \\ \text { CAD Architecture } \\ \text { CAD Envelope }\end{array}\right]$

Replacing equation 3 in equation 2 yields:

$\left[\begin{array}{c}\text { Import/Export Loads } \\ \text { Channel Loads } \\ \text { No Interfering } \\ \text { Support and Channel Loads }\end{array}\right]=\left[\begin{array}{cccc}b_{11} & & & \\ b_{21} & b_{22} & & \\ b_{31} & b_{32} & b_{33} & \\ b_{41} & b_{42} & b_{43} & b_{44}\end{array}\right]$

CAD Interface

CAD Architecture

CAD Envelope

CAD Part Body

Replacing equation 4 in equation 1 yields:

$\left[\begin{array}{c}\text { Specify Material Requirements } \\ \text { Import/Export Loads } \\ \text { Channel Loads } \\ \text { No Interfering } \\ \text { Support and Channel Loads }\end{array}\right]=\left[\begin{array}{lllll}a_{11} & & & & \\ a_{21} & a_{22} & & & \\ a_{31} & a_{32} & a_{33} & & \\ a_{41} & a_{42} & a_{43} & a_{44} & \\ a_{51} & a_{52} & a_{53} & a_{54} & a_{55}\end{array}\right]\left[\begin{array}{c}\text { Material Selection } \\ \text { CAD Interface } \\ \text { CAD Architecture } \\ \text { CAD Envelope } \\ \text { CAD Part Body }\end{array}\right]$

The matrix $\mathrm{A}\left[\mathrm{a}_{\mathrm{ij}}\right]$ in equation 5 shows an order relation in the management of CAD modelling. It shows that design modelling follows that principle: material drives the morphology. 


\section{Application}

This section proposes an application of the material skeleton approach. The case of a Laval nozzle is presented. This study case is only a demonstrator of the approach viability. It will be now essential to implement this approach into an industrial case to validate the approach for the industry.

\subsection{Material selection}

Table 1 shows an Extract of the data repositories. In this example, the fuzzy geometrical interfaces are the geometrical entities located at the interfaces of the product, meaning the rocket engine where the nozzle is plugged. For the material specifications and rules, we can retrieve, based on previous experiences and the state of the art, a set of specifications and a set of rules.

Table 1. Table extract of the data repositories.

\begin{tabular}{|c|c|c|}
\hline Repository Name & Categories & Value \\
\hline \multirow{2}{*}{$\begin{array}{l}\text { Fuzzy geometrical } \\
\text { interfaces }\end{array}$} & \multirow[t]{2}{*}{ Engine interface } & 2 Plans \\
\hline & & 2 sections lines \\
\hline \multirow[t]{7}{*}{ Design requirements } & \multirow[t]{4}{*}{ Fluid mechanics shape } & Internal spline with 6 control points \\
\hline & & $\begin{array}{l}\text { Internal shape passing through } 6 \\
\text { circles }\end{array}$ \\
\hline & & External spline with 6 control points \\
\hline & & $\begin{array}{l}\text { External shape passing through } 6 \\
\text { circles }\end{array}$ \\
\hline & Pressure & From 0,1 to $8 \mathrm{Mpa}$ \\
\hline & Temperature & From 1700 to $3300 \mathrm{~K}$ \\
\hline & Velocity & From 0 to $3 \mathrm{Mach}$ \\
\hline \multirow[t]{16}{*}{ Material specifications } & \multirow[t]{4}{*}{ Graphite } & To minimize ablation : \\
\hline & & Max pressure: $10 \mathrm{Mpa}$ \\
\hline & & Max temperature: $3500 \mathrm{~K}$ \\
\hline & & Max velocity : $>3$ Mach \\
\hline & \multirow[t]{4}{*}{ Graphite - Phenolic resin } & To minimize ablation : \\
\hline & & Max pressure: $5 \mathrm{Mpa}$ \\
\hline & & Max temperature: $2800 \mathrm{~K}$ \\
\hline & & Max velocity : > 3 Mach \\
\hline & \multirow[t]{4}{*}{ Silica - Phenolic resin } & To minimize ablation : \\
\hline & & Max pressure : 1,2 Mpa \\
\hline & & Max temperature: $2000 \mathrm{~K}$ \\
\hline & & Max velocity $:>3$ Mach \\
\hline & \multirow{4}{*}{$\begin{array}{l}\text { 4D braided Carbone / } \\
\text { Carbone composite }\end{array}$} & To minimize ablation : \\
\hline & & Max pressure: $10 \mathrm{Mpa}$ \\
\hline & & Max temperature: $3500 \mathrm{~K}$ \\
\hline & & Max velocity : : > 3 Mach \\
\hline
\end{tabular}




\begin{tabular}{lll}
\hline Repository Name & Categories & Value \\
\hline Materials rules & Graphite & $\begin{array}{l}\text { Thickness abaqus regarding } \\
\text { mechanical constrains }\end{array}$ \\
\hline Graphite - Phenolic resin & $\begin{array}{l}\text { Thickness abaqus regarding } \\
\text { mechanical constrains }\end{array}$ \\
\hline Silica - Phenolic resin & $\begin{array}{l}\text { Thickness abaqus regarding } \\
\text { mechanical constrains }\end{array}$ \\
\hline 4D braided Carbone / & $\begin{array}{l}\text { Thickness abaqus regarding } \\
\text { mechanical constrains }\end{array}$ \\
\hline
\end{tabular}

\subsection{Material skeleton}

From equations 3 the material skeleton is defined from CAD interface design, CAD architecture and CAD envelope. Figure 1 shows a section of the nozzle with fuzzy geometrical interfaces. The geometry satisfying the design requirements is represented by a fuzzy spline with 6 control points and the radius of the 6 circles forming the internal shape of the nozzle. The interaction with the engine is represented geometrically by two fuzzy segments (bottom left).

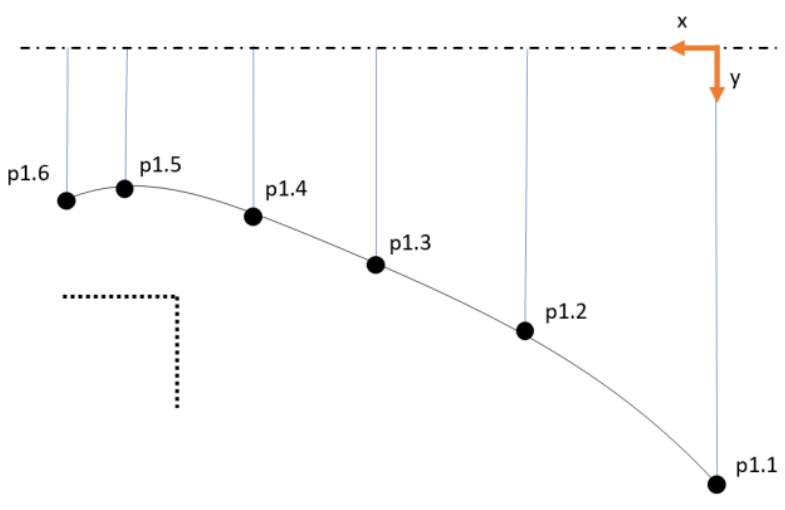

Figure 1. Section representation of nozzle with fuzzy geometrical interfaces.

\subsection{CAD interface design}

A CAD interface $i$ is a geometrical entity laid on a layer $i$. For the nozzle, it is defined by a plan and two circles representing the internal and external diameter of the nozzle. Figure 2 shows the generated interfaces. 


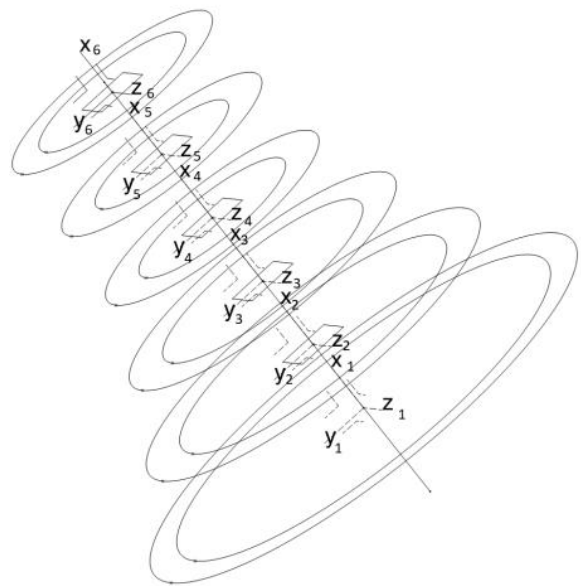

Figure 2. CAD interfaces.

\subsection{CAD architecture}

CAD architecture represents the geometrical relationship between CAD interfaces. Figure 3 represents the direct link between the interfaces. At each layer $i$, a coordinate system $R_{i}\left(O_{i}, x_{i}, y_{i}, z_{i}\right)$ is defined and associated with the interface $i$. A geometrical parameter $x_{i j}$ defines the position of the centres of the interfaces $i$ and $j$ in their respective coordinate system $R_{i}\left(O_{i}, x_{i}, y_{i}, z_{i}\right)$ and $R_{j}\left(O_{j}, x_{j}, y_{j}, z_{j}\right)$ linked to these interfaces. Geometrical parameters are associated with the geometry of each interface. The geometrical parameters: the diameter $d_{i}$ and the thickness $e_{i}$ drive the geometry of the interface. The internal spline passing respectively through the 6 control points represent the computed aerodynamical shape of the nozzle. Finally, the interfaces with the engine, are represented by 2 plans and 2 segments lying on these plans.

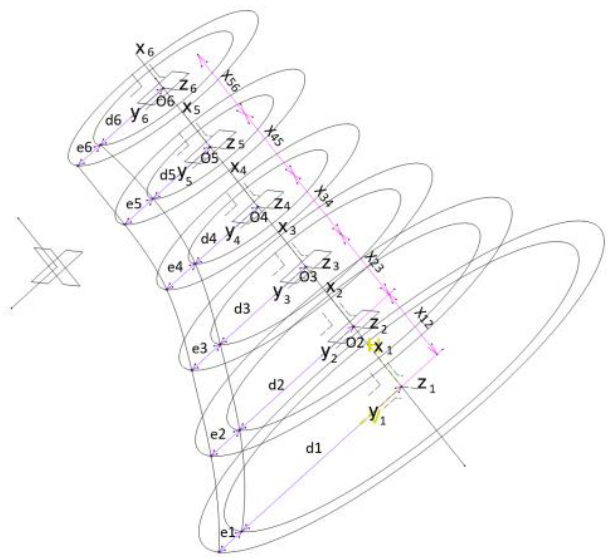

Figure 3. CAD architecture. 


\subsection{CAD envelope}

CAD envelope defines where the morphology of the nozzle can be built without interfering with other parts of the system. Figure 4 represents the limit areas of the nozzle. The internal and external surfaces of the nozzle (coloured in blue) represent the envelope of the body of the nozzle; the contact surfaces of the engine, where the nozzle will be plugged, are also generated (coloured in purple).

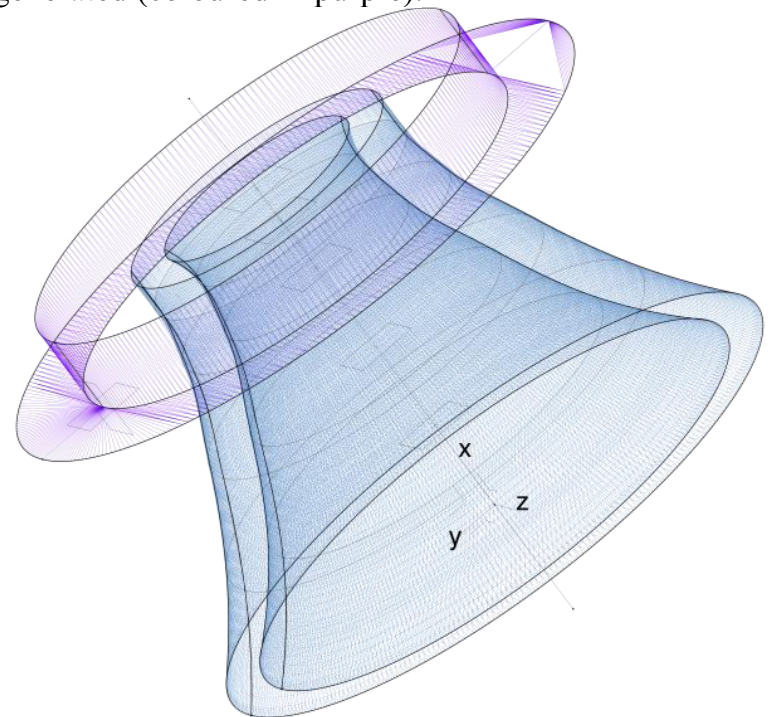

Figure 4. CAD envelope.

\subsection{Generated material skeleton}

The generic material Skeleton is composed of CAD interfaces, CAD architecture and CAD envelope (Figure 5). For each type of material, the designer can generate a specific skeleton containing the material information and a simplified morphology.

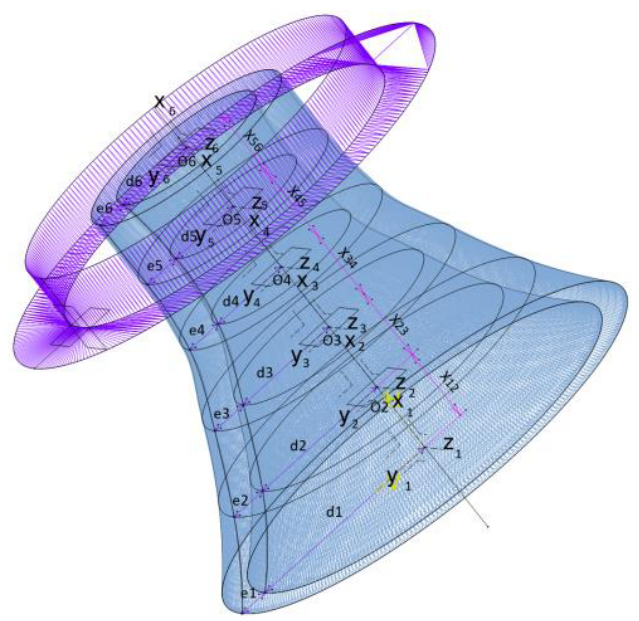

Figure 5. Generic Material Skeleton of the rocket nozzle. 
The first option is the design with multiple materials following the principle: the right material in the right place. Three types of material: Graphite, Graphite - Phenolic resin, Silica - Phenolic resin are chosen for their properties (Table 1). The thickness $e_{i}$ are updated. The multiple material skeleton is shown in Figure 6.

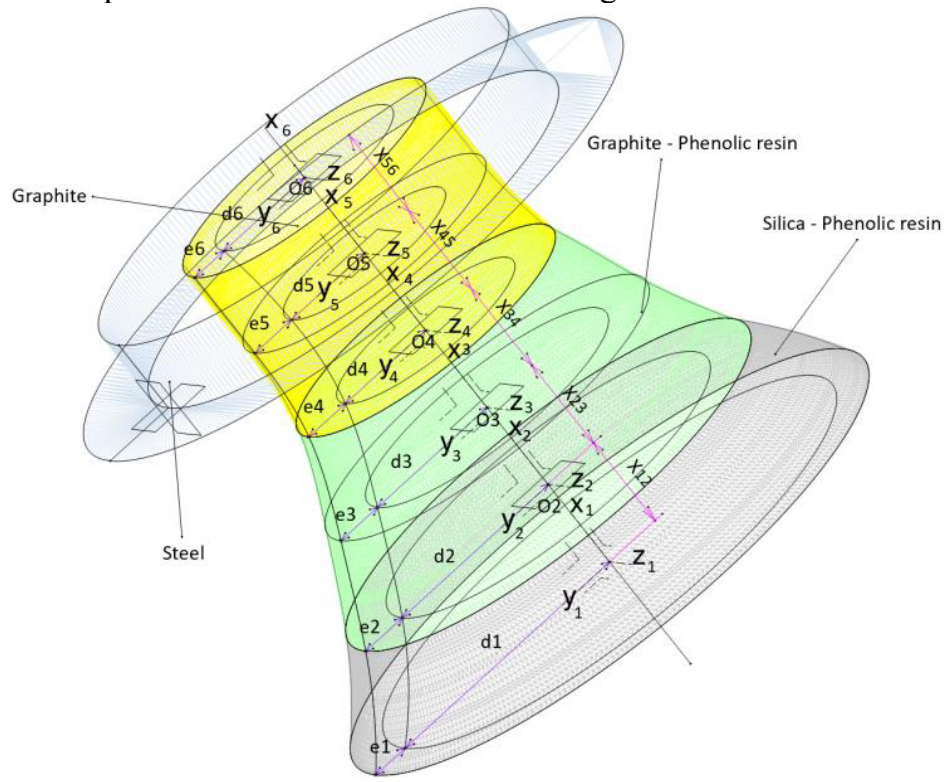

Figure 6. Multiple Material Skeleton of the rocket nozzle

The second option is the design of the nozzle with a mono-material: Carbone composite (Table 1). The mono-material Skeleton is shown in Figure 7.

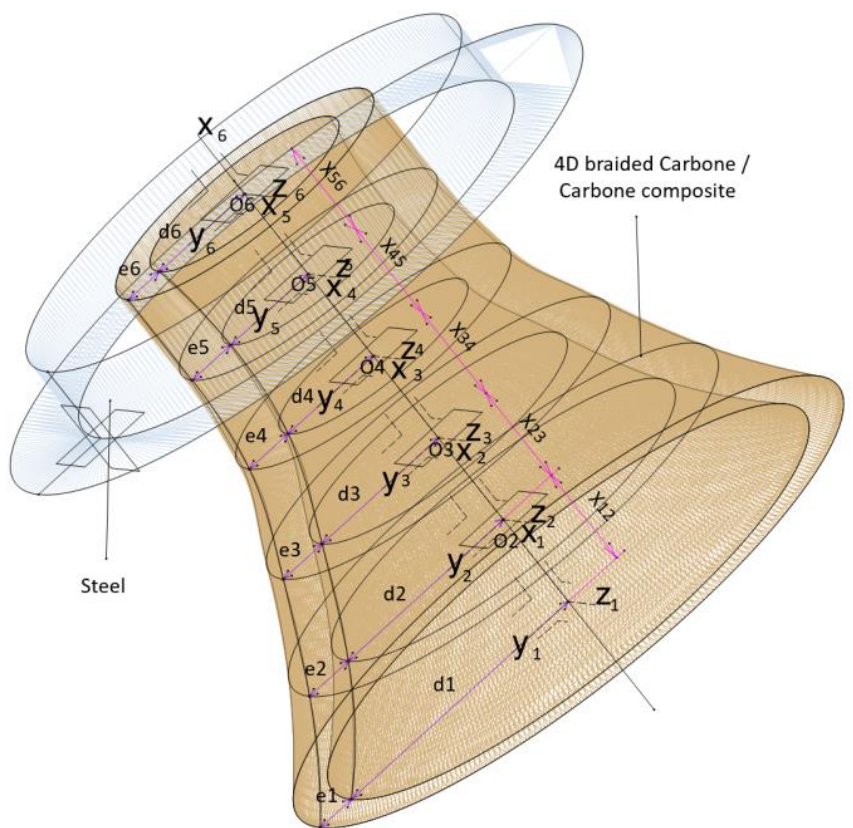

Figure 7. Mono Material Skeleton of the rocket nozzle. 


\subsection{CAD part body}

After the generation of the material skeleton, the final morphology can be directly generated based on the specific skeleton. Figure 8 shows the CAD model based on the multi-material skeleton (Graphite, Graphite - Phenolic resin, Silica - Phenolic resin). Figure 9 shows the CAD model based on the mono-material skeleton (4D braided Carbone / Carbone composite).

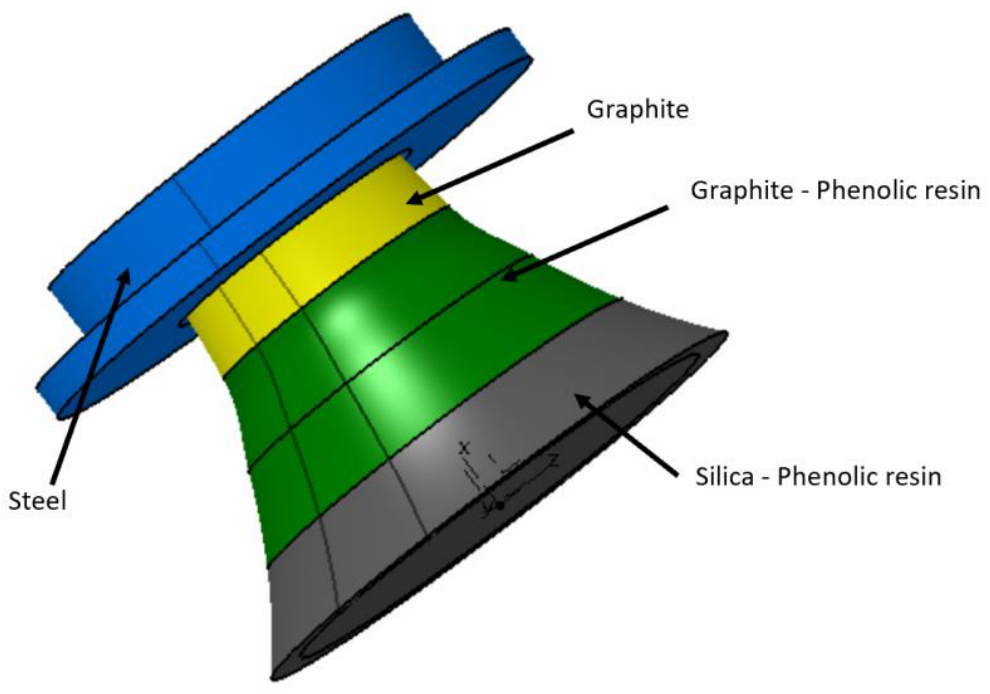

Figure 8. Product-based example on the material Skeleton for a multi-material.

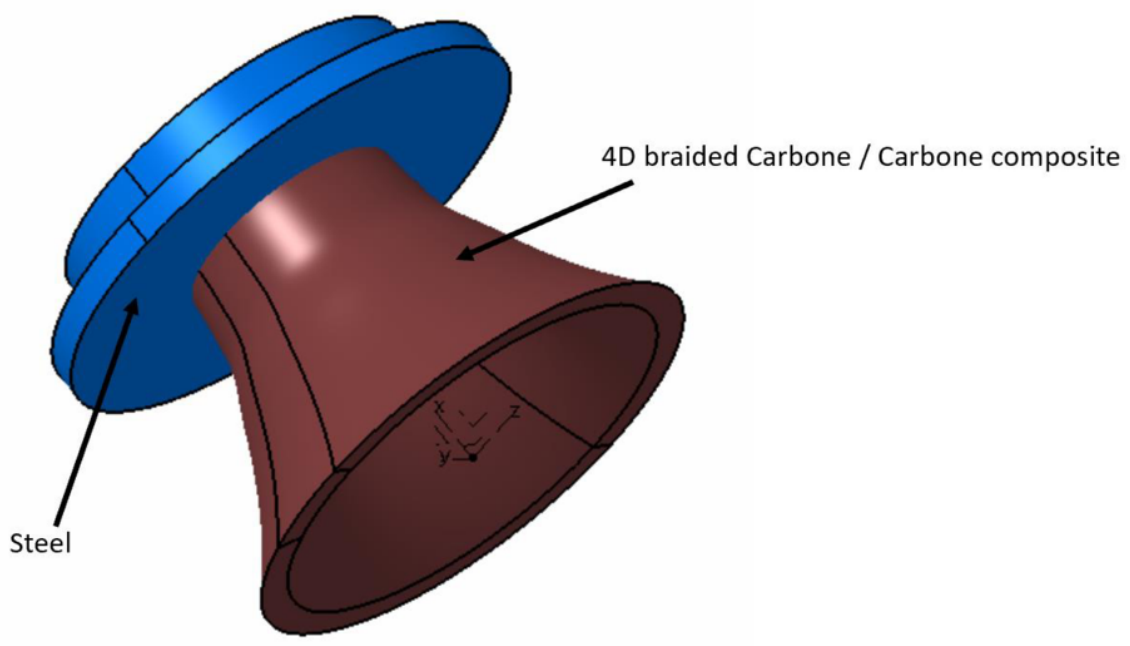

Figure 9. Product-based example on the material Skeleton for a 4D braided Carbone / Carbone composite. 


\section{Discussion and conclusion}

Today, new requirements have emerged for a sustainable design using new materials. Therefore, the morphology of the product should emerge from a primarily materialdriven design process.

Design for Material in CAD systems is an approach which satisfies the principle of the adaptive geometry driven by the sustainable material. Using the proposed formalism, the morphology of the product (geometry and topology) is formally driven by material requirements. Therefore, this approach allows the designer to design different product forms according to the material requirements of clients.

This approach structures also the definition of the material skeletons based on a cloud of points defined in an envelope [15]. This allows considering in the early phases of the design process the material specifications and distribution of engineering constraints.

Working with simplified models bring more flexibility in the design process [16]. The number of loops is reduced and the product emerges from the enrichment of a simplified model. Finally, this approach can be also adapted to different expert areas [17].

\section{References}

[1] M.F. Ashby and K. Johnson, Materials and design: the art and science of material selection in product design, 3rd ed, Butterworth-Heinemann, Oxford, 2013.

[2] Suh, N.P., Axiomatic Design: Advances and Applications, Oxford University Press, Oxford, 2001.

[3] J. Wang, B. Jiang, Y. He, Shape-based search of mechanical CAD models for product data management, International Journal of Computer Applications in Technology, 2010, Vol. 37, No.2, pp.125 - 131.

[4] A. Skander, L. Roucoules and J.S. Klein Meyer, Design and manufacturing interface modelling for manufacturing processes selection and knowledge synthesis in design. The International Journal of Advanced Manufacturing Technology, 2008, Vol. 37, No. 5-6, pp. 443-454.

[5] E. Ostrosi, J. Stjepandić, S. Fukuda and M. Kurth, Modularity: New trends for product platform strategy support in concurrent engineering, Advances in Transdisciplinary Engineering, 2014, 1, pp. 414-423.

[6] J.-B.Bluntzer, E. Ostrosi and J. Niez, Design for Materials: A New Integrated Approach in Computer Aided Design, Procedia CIRP, Vol. 50, 2016, 305-310.

[7] H. Bleyet, M. Bossmann, Automated Assembly Planning Based on Skeleton Modelling Strategy, Precision Assembly Technologies for Mini and Micro Products, IFIP International Federation for Information Processing, 2006, Vol. 198, pp. 121-131.

[8] M. Held, S. Huber and P. Palfrader, Generalized offsetting of planar structures using skeletons, ComputerAided Design and Applications, 2016, 13:5, pp. 712-721.

[9] T. Ju, M.L. Baker, W. Chiu, Computing a family of skeletons of volumetric models for shape description, M.-S. Kim and K. Shimada (eds.), GMP 2006, LNCS 4077, 2006, pp. 235-247.

[10] N.D. Cornea, D. Silver and P. Min, Curve-skeleton properties, applications, and algorithms, IEEE Transactions on Visualization and Computer Graphics, Vol. 13, Issue 3, 2007, pp. 530-548.

[11] L. Wade, R.E. Parent, Automated generation of control skeletons for use in animation, The Visual Computer, Vol. 18, 2002, pp. 97-110.

[12] N.D.Cornea, D. Silver, P. Min, Curve-skeleton applications, IEEE Visualization Conf., 2005, 1565995.

[13] F. Levet and X. Granier, Improved skeleton extraction and surface generation for sketch-based modeling, Proceedings of Graphics Interface, 2007, pp. 27-33.

[14] J. Ma and S. Choi, Kinematic skeleton extraction from 3D articulated models, Computer-Aided Design, 2014, Vol. 46, pp. 221-226.

[15] J. Lee, C. Kim, H. Son and C. Kim, Skeleton-based 3D reconstruction of as-built pipelines from laserscan data, Automation in Construction, 2013, Vol. 35, pp. 199-207.

[16] A. Biahmou, C. Emmer, A. Pfouga and J. Stjepandić, Digital master as an enabler for industry 4.0, Advances in Transdisciplinary Engineering, Vol. 4, 2016, pp. 672-681.

[17] O. Kuhn, H. Liese and J. Stjepandic, Methodology for knowledge-based engineering template update, IFIP Advances in Information and Communication Technology, Vol. 355, Springer, 2011, pp. 178-191. 